\title{
MobiSec - Automatização de Teste de Segurança Móvel
}

\author{
Mariano Florencio Mendonça ${ }^{1}$, Layse Santos Souza ${ }^{1}$, Gabriel Gonçalves dos \\ Santos $^{1}$, Guilherme Santana Florencio ${ }^{1}$ \\ ${ }^{1}$ Universidade Tiradentes (Unit) \\ Aracaju - SE - Brasil \\ \{marianofmendonca, santoslay3\}@gmail.com, gongabriel.92@hotmail.com, \\ guilherme.sflorenciodoutlook.com
}

\begin{abstract}
This article presents a tool for automating security analysis in mobile applications aimed at the android operating system. Automating the tools Androguard, Androbus and Androwarn we developed the MobiSec that is based on a test plan for execution.
\end{abstract}

Resumo. Este artigo, apresenta uma ferramenta para automatização de análise de segurança em aplicações móveis voltadas ao sistema operacional android. Automatizando as ferramentas Androguard, Androbus e Androwarn desenvolvemos o MobiSec que baseia-se num plano de teste para execução.

\section{Introdução}

Com o crescimento do mercado de dispositivos móveis e consequentemente de aplicações para diversos clientes tornou-se necessário uma maior garantia de segurança dessas aplicações. Tendo em vista essa garantia, estudamos ferramentas e critérios de segurança do sistema operacional Android.

Malek et al. (2012) reconhece que o principal obstáculo para avaliar a segurança está na quantidade de malwares que surgem diariamente. StatCounter (2018) expõe que o Android foi o sistema operacional mais utilizado em 2018.

\section{Descrição do MobiSec}

O MobiSec foi desenvolvido com o propósito de automatizar os testes de segurança em aplicações Android aspirando os resultados de ferramentas como Androguard, Androbugs e Androwarn. Para o seu desenvolvimento foi escolhida a linguagem PHP em razão da afinidade dos pesquisadores e da integração com as ferramentas citadas acima.

O processo de teste do MobiSec necessita do upload do arquivo apk da aplicação, deste modo o Androguard descompila e gera o arquivo AndroidManifest.xml contendo as informações pertinentes da aplicação que será testada, e de modo consequente confrontando o que foi planejado com o que foi desenvolvido, e assim avalia a segurança da aplicação através das permissões por ela solicitadas ao cliente final.

Após esse processo, o Androbugs analisa profundamente a apk gerando um relatório baseando-se no código fonte apontando pontos do mesmo que sejam inseguros ao aplicativo e usuário final, já o Androwarn gera um relatório sobre os prováveis comportamentos maliciosos desenvolvidos pela aplicação. Todas as atividades são gravadas em um Sistema Gerenciador de Banco de Dados (SGBD). 
Com a implementação do algoritmo SVM (Máquina de Vetores de Suporte ou Support Vector Machine) no relatório do Androbugs, conseguimos testar as aplicações que já possuíram malwares e que não possuíam para treinar a Inteligência Artificial (IA), destas aplicações $70 \%$ foram usada para treinar e $30 \%$ para verificar a funcionalidade na aplicação. A IA é aplicada no MobiSec via linha de comando já que foi desenvolvida em uma linguagem de programação diferente da que usamos em nossa ferramenta de automatização.

Figura: Plano de Teste, guia para execução da automatização de testes nos apk.

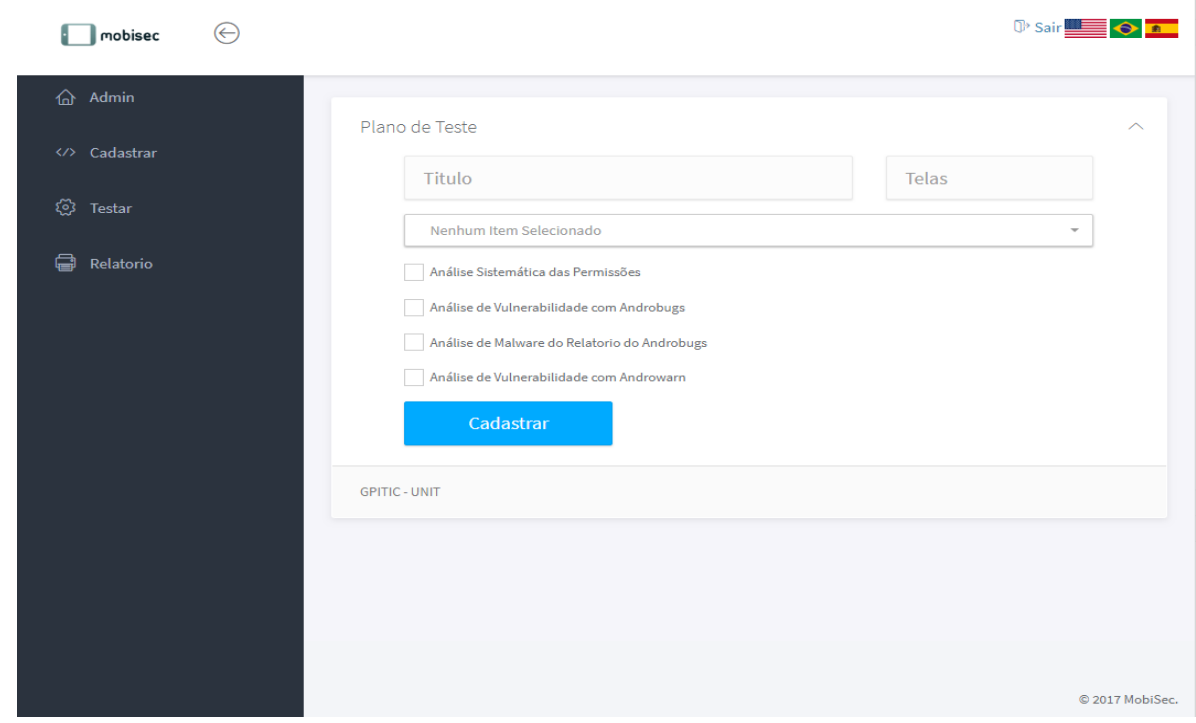

Fonte: Elaborado pelo autor

\section{Considerações Finais}

Com a automatização de ferramentas que realizam testes em aplicações e a implementação de IA é presumível determinar o grau de sucesso na segurança de uma aplicação para dispositivos Android, logo gera mais confiabilidade ao cliente final. Destarte, o MobiSec busca desenvolver uma ferramenta que possa interagir com várias ferramentas de testes em aplicações Android. Para trabalhos futuros pretende-se elaborar uma rede neural e outros métodos de análise dos relatórios gerados pelas ferramentas automatizadas. Isto pode tornar-se um incremento importante nos testes de software.

\section{Beneficios Para a Sociedade}

Automazar técnicas para análise de segurança em aplicações móveis para sistema operacional android proporciona para a sociedade aplicações mais seguras aos seus dispositivos.

\section{Referências}

Malek, Sam; Esfahani, Naeem; Kacem, Thabet; Mahmood, Riyadh; Mirzaei, Nariman; Stavrou, Angelos. (2012). A framework for automated security testing of android applications on the cloud. In SERE-C'12, pp. 35-36.

StatCounter. (2018). Disponível em: <http://gs.statcounter.com/os-marketshare\#monthly-201801-201901-bar>. 